\title{
Distance Control System to Increase Precision And Stability of Glass Cleaning Robot
}

\author{
Bambang Sampurno ${ }^{1}$, Arief Abdurrakhman ${ }^{2}$, Herry Sufyan $\mathrm{Hadi}^{2}$, Heri Joestiono ${ }^{2}$, and Amanda Fitri Saudzah ${ }^{2}$
}

\begin{abstract}
Glass is a widely used material today. One of them is as a window of a building. As the material is easily broken, glass is very vulnerable in the cleaning process. This causes the process of cleaning the glass cannot be done carelessly. To overcome these problems, one of them is to replace the work done by humans with machines or robots. The glass cleaning robot was created as a glass cleaner replacing the conventional workforce. One of the most important elements in the operation of glass cleaner robots is the robot glass distance control system against glass edges using proximity sensors. At a distance of 35 $\mathrm{cm}$, the proximity sensor will send a signal back to the microcontroller and forwarded to the input dc motor so that the value changes rpm on the motor with pwm value of 205 each for the left motor and 150 for the right motor for 1 second so that The robot will turn clockwise. From the tested, gotten the response of distance control system based on the PWM value vs time. It shows that the system has a good response to listing programs that have been created. It does not have a research value different from the setting point and fast to achieve stable conditions. In the design of cleaning fluid monitoring system on glass cleaning robot used water level sensor. It used Bluetooth as a wireless system to display height of water in container cleaning fluid.
\end{abstract}

Keywords-The Glass Cleaning Robot, Proximity Sensor, Motor DC, Microcontroller.

\section{INTRODUCTION}

Glass is a hard, fragile substance, and an amorphous solid. It's because amorphous glass materials which can melt easily. Glass is the result of the inorganic decomposition compounds which have undergone cooling without crystallization. The main component of glass is silica. Everyday glass is used as a mirror, heat insulator, laboratory equipment, decoration, and room divider.

According to Adams and Williamson, glass is an amorphous material that at ordinary temperatures has a hard form, but when heated, it will gradually become soft, corresponding to the increased temperature and eventually become viscous until it reaches a liquid state. During the cooling process, it occurs a process in contrast to the glass melting process. Glass has properties that are resistant to chemicals, effective as an electrical insulator, can withstand vacuum. In addition to having these properties, glass is a fragile material and not resistant to impact.

\footnotetext{
${ }^{1}$ Bambang Sampurno is with Department of Industry Mechanical Engineering, Institut Teknologi Sepuluh Nopember, Surabaya, 60111, Indonesia. E-mail: bsampurno1965@gmail.com.

${ }^{2}$ Arief Abdurrakhman, Herry Sufyan Hadi, Heri Joestiono, and Amanda Fitri Saudzah are with Department of Instrumentation Engineering, Institut Teknologi Sepuluh Nopember, Surabaya, 60111, Indonesia.
}

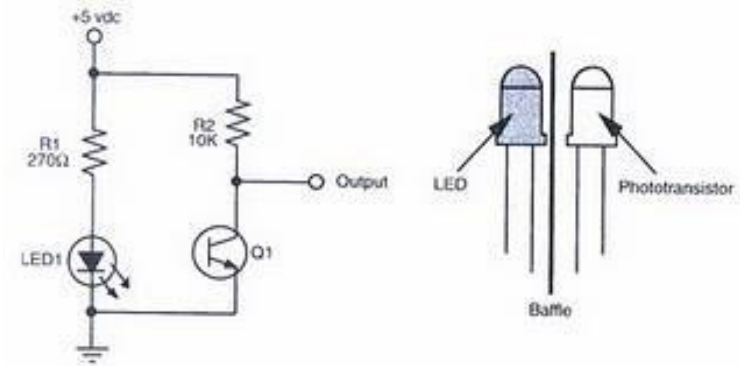

Figure 1. Basic Proximity Infrared Sensor Series [4].
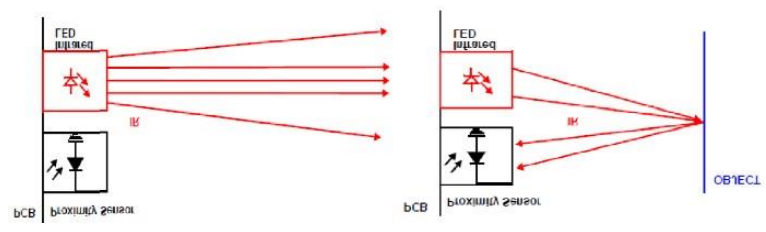

Figure 2. Working Principles of Proximity Infrared Sensor [4].

Glass are used anymore on builidng like hotels, supermarkets, apartment, office, etc. Based on the energy conversion system, a building or building has priority to support the comfort and humidity of air that requires the existence of air circulation system and natural lighting. But sometimes dirty air circulation cause the indoor room is easily dirty due to dust from the free air that enters. Therefore, air circulation coating and natural lighting in this building is the most widely used is glass. With the glass as a dust barrier will enter the building, resulting in dust and dirt from free air settles on the glass surface. If cleaning is not done, the dust and dirt will disrupt the comfort and natural lighting in the building. Therefore, glass cleaning is done routinely.

In the application, the cleaning of glass in multi-storey building still use conventional power that is by human labor. This is very dangerous because the risk of work accidents. Therefore, a robot is created to replace this conventional power to reduce accidents. The robot in question is a glass cleaning robot.

Robots require a working area to operate, so a sensor is required to limit the robot's working area. The glass cleaner robot that has been published were WINDORO and CleWiBot. Limitation of work area of this robot use remote control and ultrasonic sensor [1]. robot that use remote control is less effective because the robot cannot work automatically. Using of ultrasonic sensors is considered less effective because the cost is too large. Therefore, the sensor used is the proximity sensor. Proximity sensor is selected for the reason that sensors that work without providing direct 
contacts are perfect for detecting metallic and non-metallic objects [2]. This IR proximity sensor consists of LEDs that emit infrared light. These sensors make it possible to detect objects without influence on reflective object colors, reflectivity, environmental lights. The obstruction of the object to this proximity sensor produces a voltage which is a function of reach [3]. The output voltage is then forwarded for processing on the microcontroller. The IR proximity sensor is used to detect proximity of obstacles within short distances.

This reseach designed close-range control system for glass-cleaning robots using IR proximity sensors where the authors further strive to regulate the movement of glasscleaning robots against glass edges. The design of the distance control system in this glass cleaning robot is an ATMega8535 microcontroller based electronics circuit with dc motor as actuator and IR proximity sensor as proximity sensor.

\section{MATERIAL AND METHODS}

\section{A. Proximity Sensor}

Proximity sensor is a type of sensor. It will active when the object is stopped near him. It has nature of work indirectly [4]. The infrared proximity sensor works by detecting the presence or absence of objects blocking the rays from the transmitter to the receiver. If there is an object in that area, the rays will be interrupted and imperfect the light received by the receiver [5]. Body heat sensors or PIRs (passive infrared) can be categorized in sensors that detect movement. This sensor acts as a receiver (passive) of the infrared light emitted by every object. (Figure 1 and 2).

\section{B. Microcontroller ATMega8535}

Microcontroller is an IC chip where there is a microprocessor and memory ROM program (Read Only Memory) and RAM (Random Access Memmory). There are several vedors that make microcontroller such as Microchip, Winbond, Atmel, Philips, Xemics and others [6]. Basically what distinguishes these types are memory, peripherals and functions. In terms of architecture and instructions used, the working principle is the same on all types of microcontroller. Therefore, one of Atmel's AVR products ATMega 8535 is used due to the I / O facility is available. The ATMega 8535 has RISC technology with a maximum speed of $16 \mathrm{MHz}$ makes this microcontroller faster than the MCS 51 variant.

The initial phase of this research began with a study of literature as an effort to understand the material that support this research on "Design of Distance Control Systems on Glass Cleansing Robot using Proximity Sensor". After doing the literature study, the next it is to identify the problems obtained based on literature studies that have been done. Then designed the purpose of making this final task and then do the system design for the title of the final task performed. The design of system design includes the design of hardware and software. The design of hardware includes the mechanical design of the distance control system on the vertical glass cleaning robot located on the top, right and bottom side of the glass cleaning robot and assembling the electrical circuit of the distance control system with the ATMega8535 microcontroller. The design of the software includes a program listing the distance control system using CV AVR software. If the design of hardware and software has been done, then next is to design a good distance control system hardware and software and integrate it. If all the design of the distance control system on the glass cleaner robot can work according to the standard, then the next data is taken at the speed of dc motor rpm against time. However, if all the design of the distance control system on the glass cleaning robot can not work according to the standard, then redesign of the distance control system. After making the design has been completed with the results in accordance with the desired, then performed data analysis by utilizing the results of the performance test and control system. After all the desired results are achieved from literature studies to data analysis and conclusions are included in a report.

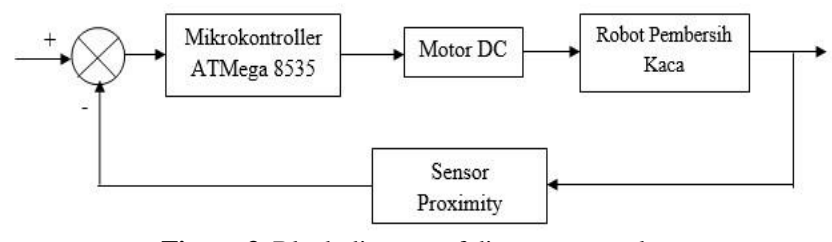

Figure 3. Block diagram of distance control system.

Figure 3 is a block diagram of the distance control system of a glass cleaning robot comprising an ATMega8535 microcontroller as a controller, a dc motor as an actuator, a glass cleaning robot for processing, and an infrared proximity sensor as a sensor for distance glass edge sensing. When the infrared beam from the IR proximity sensor is blocked by the edge of the glass, the physical quantity will be converted into voltage and then the output will be read by microcontroller ATMega8535. The data is calculated by listing the program that has been prepared. In the next stage the system can provide action on the motor DC to give rpm difference on each motor in a certain time.

\section{General Describing}

The distance control system of glass cleaning robot serves to control the movement of glass cleaner robot on glass edges. This glass edges have a minimum value of $5 \mathrm{~cm}$. In normal conditions, the IR proximity sensor emits infrared light with high conditions. When there is a hindrance that is in the form of glass edges, infrared rays are blocked by glass edges causing a reflection from the sending beam to the receiver. This results in a change in the value of the proximity sensor. Figure 4 describes design of Glass Cleaning Robot. This robot is moved to use DC motor that connects with suction cup. Suction cup are used to stick on glass, so the robot don't be falled. There are cleaner fluid and fabric to clean glass.

In the glass cleaning robot, there are 3 proximity sensors that serve to detect the glass barrier top, right and bottom glass cleaning robot (Figure 4). At the beginning of the operation, the glass cleaning robot should be placed on the bottom left corner of the glass. 
International Conference on Engineering, Advance Science and Industrial Application (ICETESIA) 2018

September 6-7 2018, Institut Teknologi Sepuluh Nopember, Surabaya, Indonesia

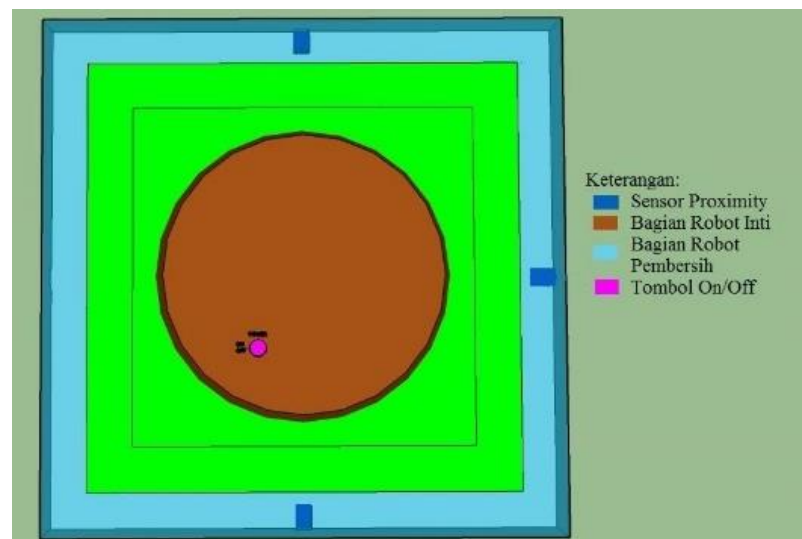

Figure 4. Glass Cleaning Robot was looked from top.

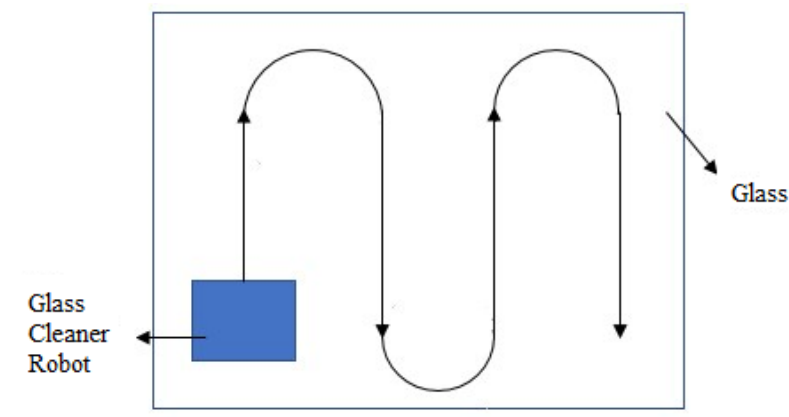

Figure 5. Cleaner clearance of glass cleaning robot.

When the glass cleaner robot is turned on, the DC motor will move with default of straight movement. When the top proximity sensor detects the edge of the glass, the proximity sensor sends a signal to the ATMega8535 microcontroller to process the signal from the top proximity sensor to reduce and accelerate rpm of DC motor for 1 second. After, DC motor will move as default again until the right proximity sensor detects glass edge. When glass cleaning process has been completed, DC motor will stop moving with command that proximity sensor under robot changed value or obstructed by glass edge. As for the path of cleaning glass as shown in Figure 5.

\section{Design of Distance Control Systems}

In distance control system has 2 parts namely core of machine that has dimensions $(32 \mathrm{~cm} \times 10 \mathrm{~cm})$ and part of cleaner $(53 \mathrm{~cm} \times 53 \mathrm{~cm})$ using the forming material is aluminum. The working principle of distance control is to change speed of each motor rpm in according set point.

\section{E. Designing and Making Software}

In control system, there are several programs required by the system, namely:

1) Program to set state when the top proximity sensor of robot detects the edge of the glass.

2) The program to set state when the bottom proximity sensor of robot detects glass edges.

3) Program to regulate the state when the lower and right proximity sensors of robot detect the edge of the glass.

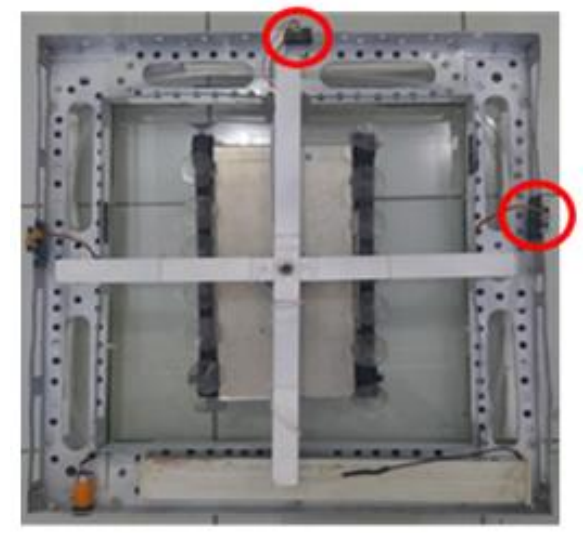

Figure 6. Proximity sensor is on glass cleaning robot.

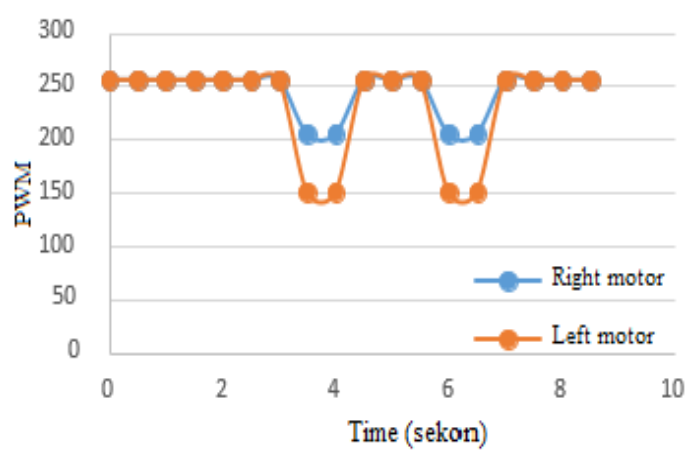

Figure 7. Graph of Distance Response Control System Against Value PWM Motor.

4) The program is simulated and created using CodeVision AVR software.

\section{RESULT AND DISCUSSION}

Distance control system on the glass cleaning robot used 2 pieces of IR proximity sensor. Sensors used in this control process is the IR proximity sensor Sharp GP2Y0A41SK0F which has a range of readings of $4-30 \mathrm{~cm}$. The IR Sharp GP2Y0A41SK0F proximity sensor is mounted on a glass cleaning robot as shown in Figure 6. The Sharp GP2Y0A41SK0F IR proximity sensor is each installed to detect upper, right and left glass edges with a minimum height of $5 \mathrm{~cm}$ glass rim.

The IR Sharp GP2Y0A41SK0F proximity sensor is installed to detect the upper, right and left glass edges with a minimum height of $5 \mathrm{~cm}$ glass rim.

Sensor testing is done to find out the sensitivity of the sensor. The test is done by activating the reference voltage of $5 \mathrm{~V}$ that goes into the sensor, then measured the voltage value that will be read as obstacle object. The voltage values obtained from the measurement of ADC values are converted directly by the microcontroller and displayed.

The graph in Figure 7 illustrates the response of distance control system based on the PWM value vs time. The graph shows that the system has a good response to listing programs that have been created. It does not have a research value different from the setting point and fast to achieve stable conditions. Meanwhile, Figure 8 is to know the turn angle of the glass cleaning robot. 


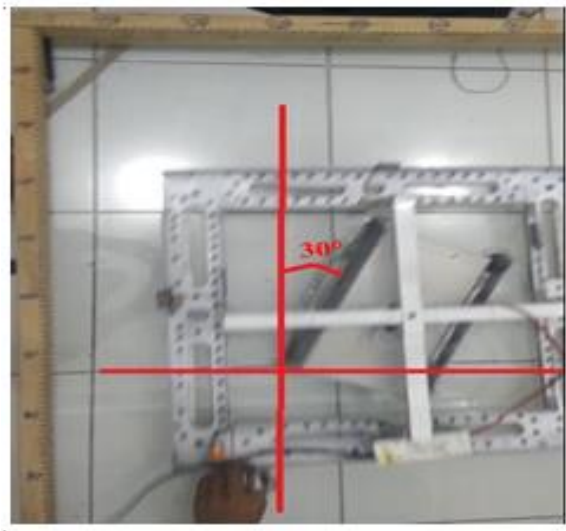

Figure 8. Turning corner of Glass Cleaning Robot.

\section{CONCLUSION}

Based on the results of research that has been done can be concluded as follows:

1. In glass cleaning robot, used 2 pieces of proximity sensor located at the top and right of the robot. When the proximity sensor changes value, from high to low, the sensor will send the signal to microcontroller for processed and forwarded to DC motor, so PWM value for right and left motors were different and the robot will turn with an initial angle of $30^{\circ}$ and continue to turn up to $90^{\circ}$ from starting position for 1 second and back straight.

2. From testing, gotten the response of distance control system based on the PWM value vs time. It shows that the system has a good response to listing programs that have been created. It does not have a research value different from the setting point and fast to achieve stable conditions.

3. In the design of cleaning fluid monitoring system on glass cleaning robot used water level sensor. It used Bluetooth as a wireless system to display height of water in container cleaning fluid.

\section{REFERENCE}

[1] M. Jemat, "Cleaning-Wiping Robot (CleWiBot)," 2014.

[2] M. Parbat, M. Tiwari, and J. Singh, "Arduino Base Capacitive Proximity Sensor with Midiplayer," Int. J. Electr. dan Electron. Res., vol. 3, no. 2, 2015.

[3] R. Nachmmai, G. Lavanya, N. M. Kansara, and R. Gopalakrishnan, "Obstacle Detection and Path Crossover using Fire Bird V Robot,” Int. J. Sci. Res. Dev., vol. 3, no. 11, 2016.

[4] Hutapea and Nego Sudianto, "Sensor Application in a Garbage Container Robot," 2006.

[5] F. M. Sigit, "Proximity Sensor Design based on Capacitive for Automatic Door Control," Surabaya, 2010.

[6] W. N. Riantiningsih, "Home Based Security Microcontroller ATMega 8535 with Information System by Using PC,' Medan, 2009. 